\title{
EMERGENCY RESPONSE DURING DISASTROUS SITUATION IN DENSELY POPULATED URBAN AREAS: A GIS BASED APPROACH
}

\author{
Md. Mehedi HASNAT ${ }^{1}$, Md. Rakibul ISLAM ${ }^{*}$, Md. HADIUZZAMAN ${ }^{3}$
}

DOI: $10.21163 / G T \_2018.132 .06$

\begin{abstract}
:
Geographical Information System (GIS) has widely been used in various steps of emergency management to contain the damages during any natural or manmade disasters within limit. This study presents how effectively GIS can be used for emergency management for one of the most densely populated areas of Dhaka, the capital of Bangladesh. With the first-hand baseline information from field survey an optimum route model has been proposed to represent the travel time of road network in congested scenario. The vulnerable parts of the study area are exposed based on emergency response time of firefighting stations and medical facilities, and distance from evacuation points. Some emergency response units have been suggested to enhance the disaster preparedness of the study area. Furthermore, the state of practice spatial analyses method presented in this study can be utilized in different spatial scales especially in regard to developing countries.
\end{abstract}

Key-words: Disaster response, Spatial analysis, Emergency management, Network analysis, ArcGIS.

\section{INTRODUCTION}

Bangladesh is ranked as the fifth most natural disaster-prone country in the world (Martin, 2011). With a population of 19.58 million in 2018 with a growth rate of $3.62 \%$, Dhaka, the capital of Bangladesh, is considered to be one of the most densely populated cities in the world (Islam, 2018). Different kinds of natural and man-made disasters have become a growing concern for this megacity. Particularly, the older part of the city is relatively more vulnerable to earthquake and it is overdue for Bangladesh as it experienced large earthquake last in 1897. The densely constructed old and unreinforced masonry buildings along with narrow local streets make the locality more vulnerable to earthquake damages. Rapid urbanization, high density of population and high-rise structures are making the situation worse (Rahman et al., 2015).

Recently a study showed that among the total reported fire incidences in Bangladesh, number of incidents were $2669(18.17 \%), 2422(15.36 \%), 2794(15.96 \%)$ and 2891 $(16.14 \%)$ occurred in greater Dhaka district in the year of 2010, 2011, 2012 and 2013 respectively which shows an increasing trend in terms of number of occurrences. These result into huge economic loses of 1470, 960, 2400, 4070 million BDT accordingly. This study also identified older Dhaka as "Extremely high fire incidental zone" (Tishi \& Islam, 2018).

\footnotetext{
${ }^{1}$ NC State University, Department of Department of Civil, Construction, and Environmental Engineering, 27607 Raleigh, NC,USA,mhasnat@ncsu.edu;

${ }^{2 *}$ Dhaka University of Engineering and Technology (DUET), Department of Civil Engineering, 1707 Gazipur,Bangladesh, rakibul10@duet.ac.bd;

${ }^{3}$ Bangladesh University of Engineering and Technology (BUET), Department of Civil Engineering, 1000 Dhaka, Bangladesh, mhadiuzzaman@ce.buet.ac.bd;
} 
In recent past, the capital Dhaka has experienced several fatal building crashes mostly caused due to poor construction. Unplanned and congested road network delayed the rescuing operation leading to an abnormal death penalty. The most recent incident took place on 24 April 2013, where a nine-storied building 'Rana Plaza' collapsed in Savar killing 1127 people and more than 100 are still missing (Rahman et al., 2015). Some inherent weaknesses of the transportation network of this mostly unplanned (73\% fully unplanned) city make any kind of risk management a daunting task (Mahmud \& Hoque, 2010).

It is high time for a developing country like Bangladesh to adopt an advanced systematic approach to assess any imminent risk, respond quickly, and thereby keep the damages at bay with the limited available resources. In this regard, Geographic Information System (GIS) has been proving a vital tool to locate, respond, manage, and mitigate the impact of disastrous incidents and is successfully used for different phases of the disaster management, starting from planning (Montoya, 2003) and risk assessment (Church \& Cova, 2000) to response (Laefer \& Pradhan, 2006), recovery (Gunes \& Kovel, 2000) and evacuation (Chang et al., 1997). The specific objectives of this study are to: geocode the existing land use and road networks of the study area; develop an optimum route model to be used in the network analysis; map the effective service areas of the existing emergency response facilities (i.e. Fire Stations, Hospitals, etc.); find out the most vulnerable sections of the study area and suitability analysis for initiating new facilities. The outcome of this study will provide detail information about the existing disaster management capabilities of the study area and will help to identify the most vulnerable groups of people during any disaster and thus locate critical locations for new response facilities. The optimum route model intended to be developed in this study can be used for the other parts of Dhaka city with the basic framework including particular inputs.

\section{LITERATURE REVIEW}

Emergency management activities can be grouped into five phases; planning, mitigation, preparedness, response and recovery (Hoyos et al., 2015). Mitigation Phase relates to analytical modeling and reveals the inherent spatial variation in hazard, vulnerability and ultimately risk. For natural hazards, the hazard model is generally either an inductive combination of the hazard layers (spatial coincidence) or a deterministic model of a physical process (Goodchild et al., 1994). Conducting vulnerability studies using GIS is a relatively new research area, but the potential for GIS to illuminate spatial issues in this area is becoming clear (Emani et al., 1993; Nicoară \& Haidu, 2011).

One of the hallmark applications of GIS in Preparedness Phase and Response Phase is automated mapping. Dunn and Newton (1992) have examined the potential role of GIS in generating alternative evacuation routes. Silva et al. (1993) developed and integrated an evacuation simulation model into a GIS to support the development of evacuation contingency plans around nuclear facilities. Cova and Church (1997) described a GIS-based method for revealing potential evacuation difficulties in advance of a disaster.

GIS in Recovery Phase is an initial priority of performing a cursory damage assessment to minimize the time necessary to apply for government relief. The Global Positioning System (GPS) is also invaluable in this phase for gathering locational information. During the Oakland fire, GPS and GIS were used to map the fire perimeter and geo-reference the location and number of each damaged or destroyed structure (Difani \& Dolton, 1992). Mitchell (1998) described how the fire department in the city of Tacoma, 
Washington used GIS to create response zones for all its functional fire stations. Amdahl (2001) pointed out the vital uses of GIS in the fire service is its ability to geocode individual incident point and present them on a map.

Church (1997) subtly reviewed the existing studies linking GIS and facility location problem and concluded that GIS has the ability to support a wide range of spatial queries that aid optimum location allocation. In GIS, an optimum route is found out by using shortest path analysis of Network Analysis tools. Haidu and Nicoară (2011) applied GIS procedure for the identification of existing infrastructure in the flooding areas to Baciu commune, having 7 settlements, situated in Cluj County, Romania. Ivan and Haidu (2012) outlined the importance and the efficiency of using GIS in collecting, processing and analyzing data and stated GIS as an effective tool for displaying the spatial distribution of accidents along the road network. They also concluded that GIS enables the rapid processing and display on the map of the information regarding accidents and it is useful in making decisions regarding the reduction and prevention of accidents. Nicoară and Haidu (2014) modeled the shortest path and closest facility problems for an ambulance to travel through a road network by creating a system based on GIS technology and applying it on the city of Cluj-Napoca, Romania. Panahi and Delavar (2008) developed a spatial decision support system (SDSS) for emergency vehicle routing by applying Dijkstra's algorithm in spatial analysis tool of ArcGIS and concluded that dynamic vehicle routing is an efficient solution for reduction of travel time in emergency routing and powerful tool for network analysis, visualization and management of urban traffic network.

In the context of Bangladesh, Kamal (2008) used GIS mapping technique to establish a flood risk assessment for Ward no 25, 27, 28 in Dhaka city. The main motive was to develop a risk assessment procedure to estimate the flood risk of the study area. Alam and Baroi (2004) presented an assessment of the risk of fire hazards in Dhaka City in a GIS framework in order to develop a methodology to generate fire hazard categories and risk mapping. Islam and Adri (2008) tried to explore the existing capacity of Fire Service and Civil Defense authority in Dhaka city and the preparedness of the citizens in combating fire accidents. Ansary and Choudhury (2003) presented an analysis of Dhaka City's growth and population, the occurrence of different natural disasters and disaster scenarios using GIS mapping. Maniruzzaman et al. (2001) developed a prototype Response Estimation System for Cyclones under Emergency (RESCUE), a GIS-based aid for disaster management. Azad et al. (2013) proposed a conceptual model for dealing the disaster and its management through the incorporation of mobile technology with GIS in Bangladesh. Majority of academic articles and researches acknowledge the undisputed role of GIS in the various phases of emergency response, especially, placing more emphasis on the fire and rescue service. Thus, it can be inferred that GIS can be utilized by fire service to produce an effective and efficient emergency response during a disastrous situation in densely populated urban areas.

\section{STUDY AREA}

The study area is located in the Dhaka South City Corporation (DSCC), ward no. 26, 27, 2933 and 34. In Bangladesh, "Ward" is a local administrative unit and an optional division of a city or town, especially an electoral district, for administrative and representative purposes (Sikder et al., 2018). Namely, the locations are Bakshi Bazar, Siddiq Bazar, Chawk Bazar, Naya Bazar, Tanti Bazar, Kotowali, Islampur, Sadarghat, Mitford, Shoari Ghat, Bongshal, Babu Bazar, Lalbagh. Fig. 1 shows the location and 
boundary of the study area. The study area is surrounded by 2 major roads, ZahirRaihan Road at the north side, Sadarghat-Gabtoli Road at the South, and two minor roads, Kazi Alauddin Road at the East and Bakshi bazar road at the west side. The rationale behind selecting this section of the city are a high density of population, nearly 1,22,000 to 1,44,000 per Sq. Km (Ansary and Choudhury, 2003), unplanned development, narrow and insufficient road network, and recent disastrous incidents in the selected localities. Additionally, the study area lays in moderate liquefaction susceptibility zone in Dhaka, therefore higher population density increases the possibility of greater damage ratio (as high as 40\%) (Ansary \& Choudhury, 2003). According to Alam and Baroi (2004), twentyfive fire incidences per ward are found to occur in the study area as it is located in moderately fire hazardous zones. Due to unplanned development, the land use pattern coupled with inefficient road network poses more threat for recovery and mitigation from various disastrous situations.

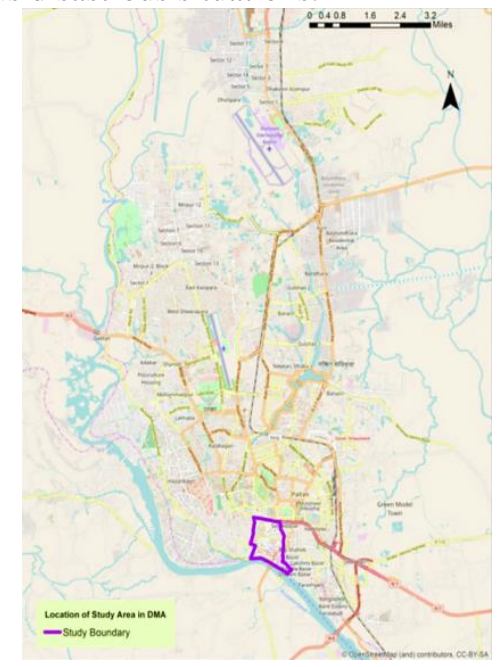

(a)

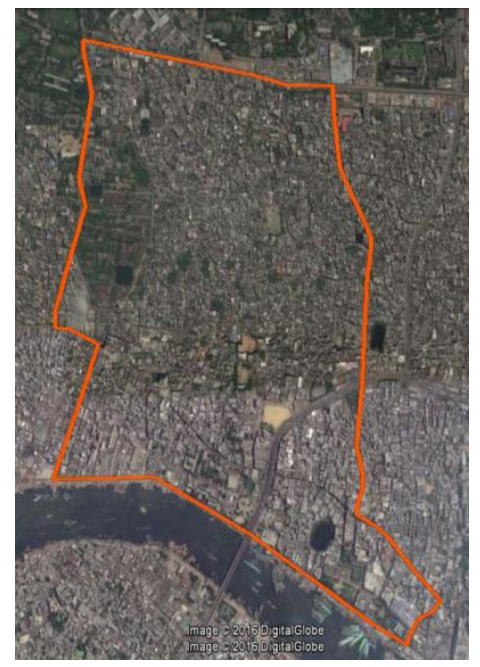

(b)

Fig. 1. Locations of the study area: (a) Location in the Dhaka Metropolitan Area; and (b) Boundary of the Study Area.

\section{METHODOLOGY OF THE STUDY}

ArcGIS 10.3 Desktop software has been used in this study is a comprehensive, integrated and scalable system designed to perform various GIS analysis ranging from simple to complex analysis such as mapping, data management, geographic data analysis, editing, and geo-processing functions. The analyses used from the ArcGIS network extension include closest facility location, Origin-Destination (O-D) cost matrix generation, location-allocation, and service area analysis. As the shortest path is prerequisite to every analysis, a comprehensive and realistic shortest route model is proposed in this study and validated using field data.

\subsection{Developing Road Network of Study Area}

As there are no databases available with the level of details to be used in this research, the road network data was mapped in Esri shape file format in ArcGIS. For this purpose, 
first-hand data about the type, width, number of lanes were collected from field survey. Total $53.37 \mathrm{Km}$ of the road network has been mapped within and adjacent to the study area. The roads have been classified into three different types based on their traffic, connectivity, lane width, travel speed. We measured the free flow speed and congested speed from travel time survey for different road types as shown in Table 1. To develop the initial road network dataset, we included the average free flow travel speed (measured at early morning from 6 am to $7 \mathrm{am}$ ) as a link attribute for each type of road (major, minor or dead end).

Table 1.

Field Data of Average Travel Speed in Different Roads in Different Scenarios.

\begin{tabular}{|c|c|c|c|c|}
\hline \multirow{2}{*}{ Road Type } & Traffic Condition & $\begin{array}{c}\text { Walking speed } \\
\mathrm{Km} / \mathrm{hr}\end{array}$ & $\begin{array}{c}\text { Rickshaw Speed } \\
\mathrm{Km} / \mathrm{hr}\end{array}$ & $\begin{array}{c}\text { Drive speed } \\
\mathrm{Km} / \mathrm{hr}\end{array}$ \\
\hline \multirow{2}{*}{ Major Roads } & Free Flow Condition & 3.6 & 8 & 15 \\
\cline { 2 - 5 } & Congested Condition & 3.6 & 4 & 8 \\
\hline \multirow{2}{*}{ Minor Roads } & Free Flow Condition & 3.6 & 5 & 10 \\
\cline { 2 - 5 } & Congested Condition & 1.8 & 2.5 & 5 \\
\hline \multirow{2}{*}{$\begin{array}{c}\text { Roads with Dead } \\
\text { end }\end{array}$} & Free Flow Condition & 3.6 & 4 & 5 \\
\cline { 2 - 5 } & Congested Condition & 1.8 & 2 & \\
\hline
\end{tabular}

However, from the field survey we found that during different times of the day even in the same type of road or in upstream and downstream of the same road the travel time varies by a significant value. The various friction points as mapped in Fig. 2 of the network cause this delays. To address this phenomenon, we developed a friction network in which we have assigned 2 seconds delay for the friction nodes in between two junctions and 4 seconds delay for the junctions.

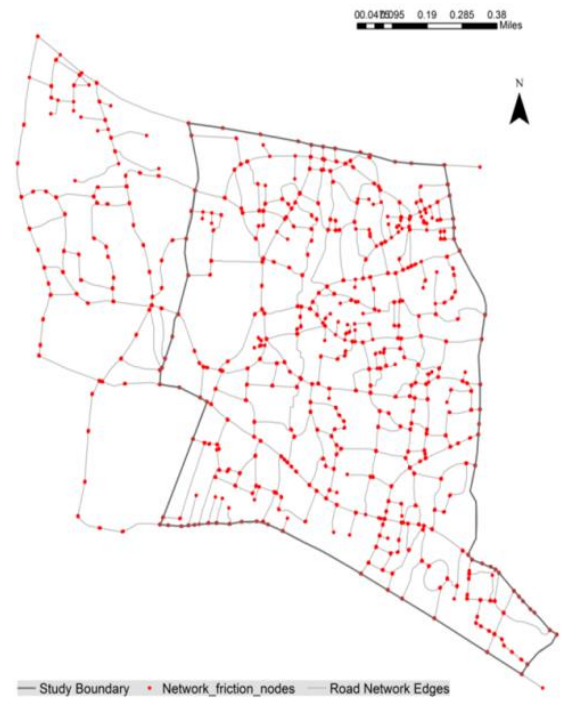

(a)

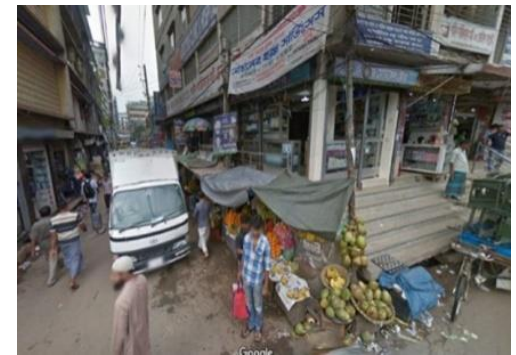

(b)

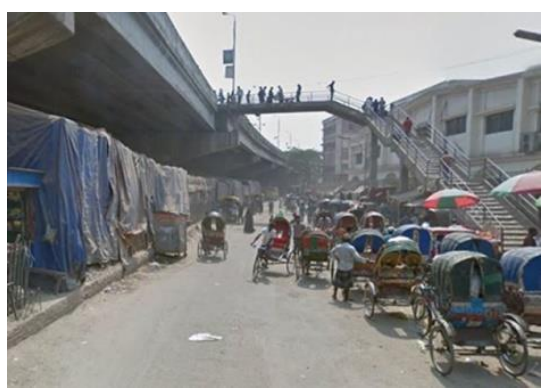

(c)

Fig. 2. Frictions in the Road Network: (a) Geo-Coded Friction Nodes; (b) Friction Nodes in the Road Network Junction; and (c) Friction Nodes in the Road Network Link. 


\subsection{Geo-Coding Land Use Types}

The whole study area is divided based on land the use pattern. Among the various uses, twelve significant land use types have been mapped in an ArcGIS shape file as in Fig. 3(a). $62 \%$ of the areas are residential plots, $8 \%$ commercial land, $8 \%$ governmental institutions, $7 \%$ mixed (commercial and residential) etc. The governmental institutions cover $8 \%$ of the area. In this type, the larger area was covered by the central jail. However, during the course of the study, the central jail has been moved to a new location. Presently, this establishment is used as a visitor's site for exhibition. For the ease of analysis, the whole study area is divided into sixty different locations prioritizing their land use pattern. The centroids of the selected locations were found out in 'WGS 1984 Web Mercator Auxiliary Sphere' projection system. Then the individual areas were calculated using Arc-GIS Field Calculator. Among the sixty analysis zones, there are 20 residential, 2 open spaces, 15 mixed, 5 commercial, 1 governmental, 1 educational, 1 hospital and 1 heritage sites in the study area. The nearby fire stations and hospitals are shown in Fig. 3(b).

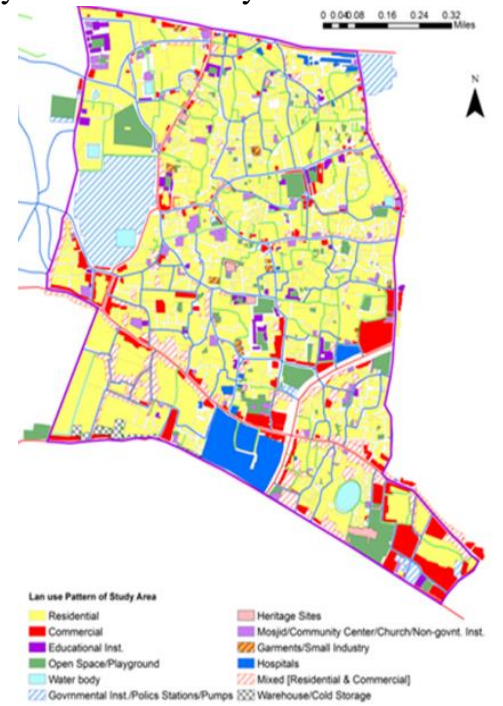

(a)

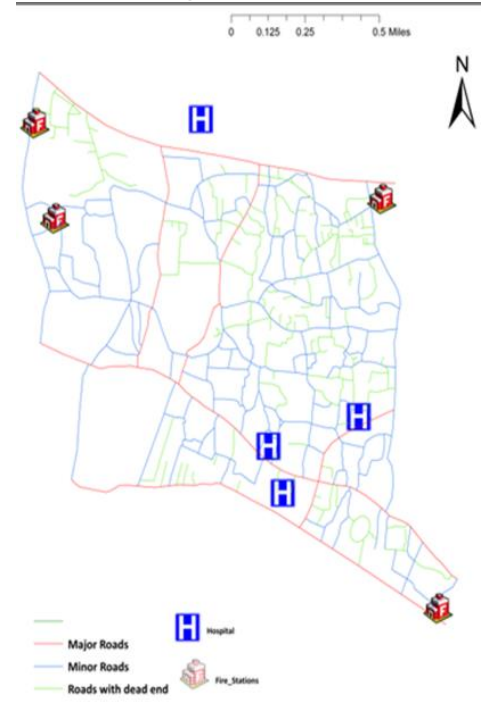

(b)

Fig. 3. Road Network and Land Use Pattern of the Study Area: (a) Road Network with location of Hospitals and Fire Stations; (b) Land use Pattern of the Study Area.

\subsection{Development and Validation of Optimum Route Model}

A realistic optimum route model has been developed by using the weighted overlay of three different cost values i.e. land use pattern, travel time (car), road network and population density. The percentages of weightage include $60 \%$ in travel time calculated from the average speed and length of links, $10 \%$ in land use types along which a route runs, $10 \%$ in population density which is maintained as a constant in this small area, and $20 \%$ in road network frictions. The purpose of the model is to estimate the field travel time during congested traffic condition. Fig. 4 represents the framework of the developed model from a single origin (Siddique bazar fire station) to all other origins (60 analysis zones). 


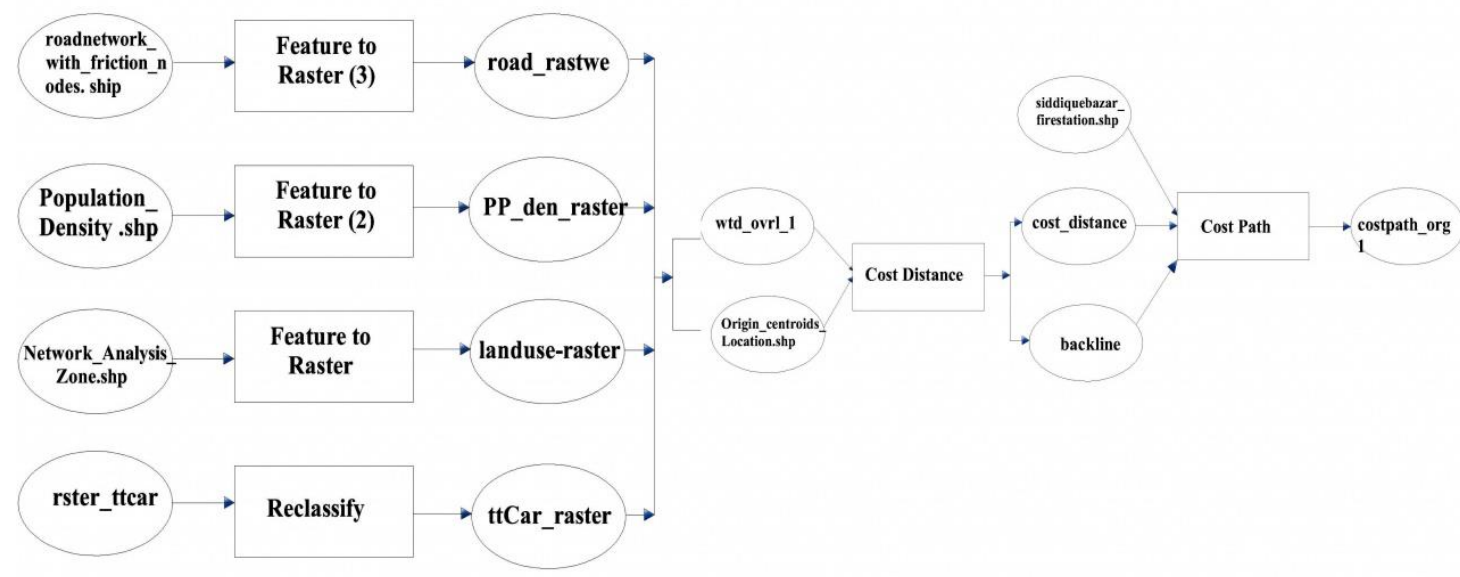

(a)

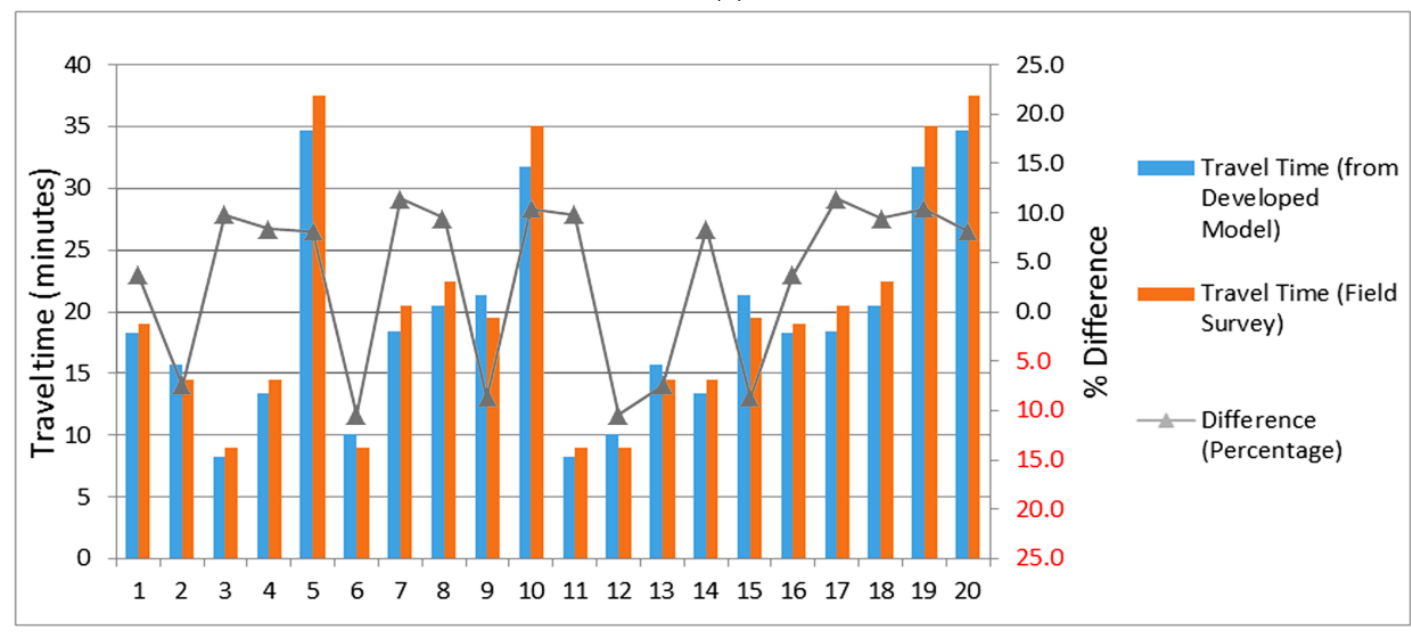

(b)

Fig. 4. Model Development: (a) Outline of Developed Optimum Route Model; and (b) Validation of Model Results with Field Data.

The outputs of the analysis using this model have been validated using field data. From the O-D cost matrix, using the scenario of the congested road network, the least travel time routes were found out. The particular routes were surveyed and travel times in peak hour were found out using the moving observer method. The difference found in developed models values and field data ranges from $11.4 \%$ to $10.5 \%$. Also, it was found that around $70 \%$ of the time the differences are below $10 \%$ range. Hence, the model is considered to be fairly realistic to be used in this study.

\section{EMERGENCY RESPONSE DURING DISASTER}

\subsection{Fire Breakout}

A total of four firefighting stations are situated adjacent to the study area. Their locations have been mapped in the ArcGIS shape file. The exact coordinates are taken from 
Google Earth. From network analysis tool, Origin-Destination analysis has been done with the localities as destinations and the firefighting stations as the origin.

From the O-D, the least travel time is found for 60 analysis zones to four firefighting stations in both free flow and congested scenario. In more detail analysis, it is found that during congestion scenario some of the localities have different fire station with less response time than free flow scenario. From Fig. 5(a), it is seen that some of the localities have increased response time up to $1100 \%$, however, in respect to the increase in travel time, the highest increase is 42 minutes.

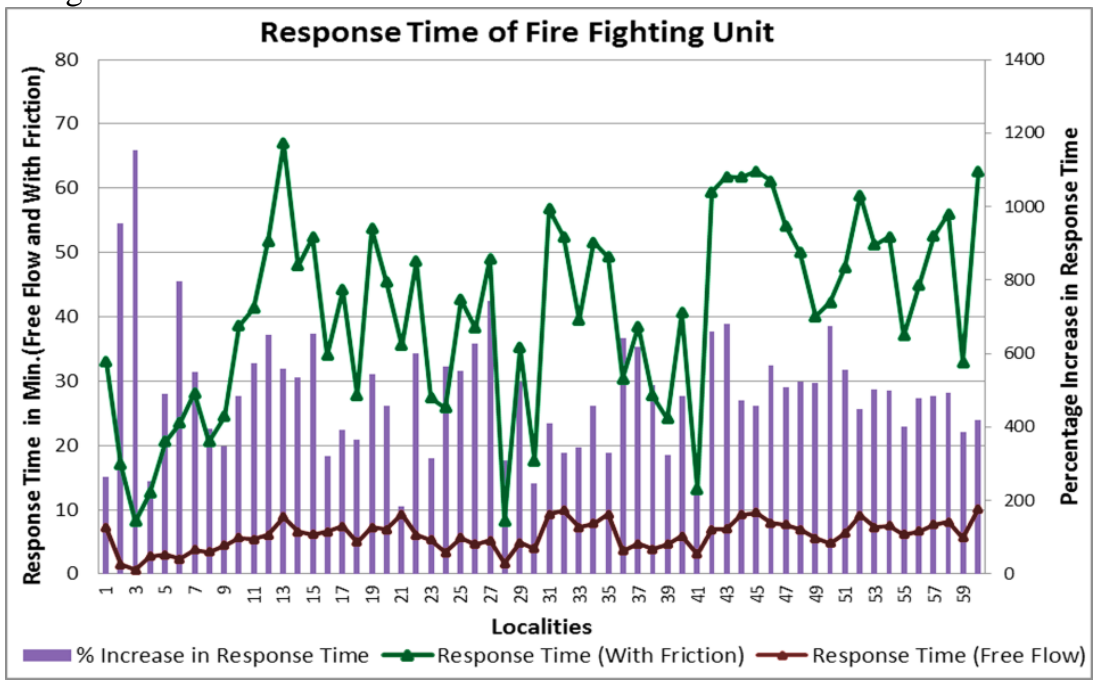

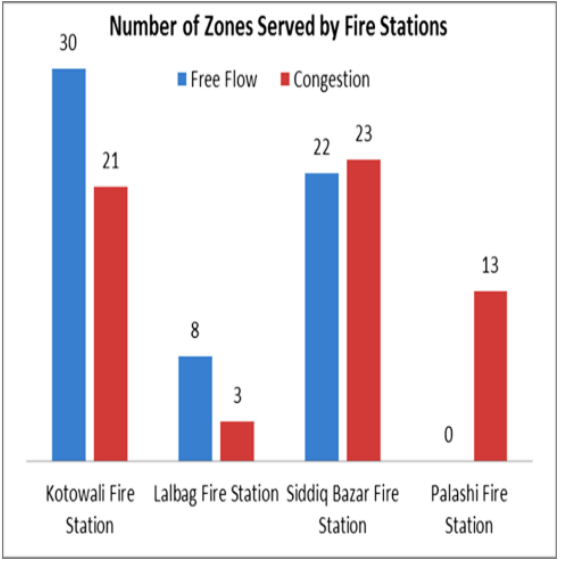

(b) (a)

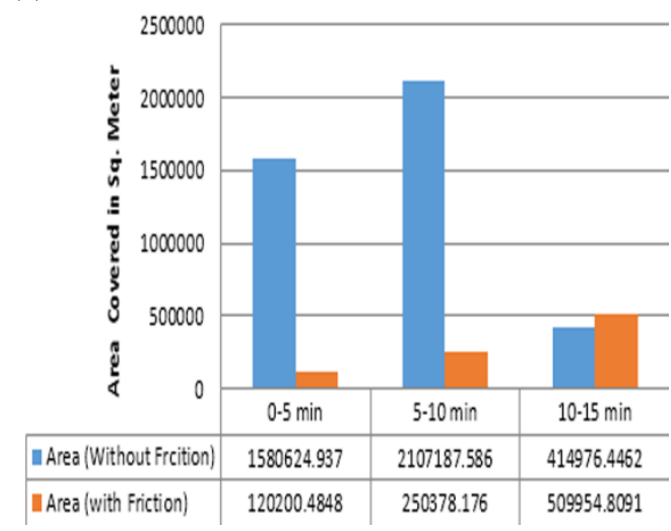

(c)

Fig. 5. Emergency Response during Fire Incidents: (a) Response Time of Fire Fighting Unit to Different Localities of the Study Area; (b) Number of Zones Served by Fire Stations; and (c) Service Area (Sq. meter) of Fire Station.

Fig. 5(b) shows the closest fire station during any fire incidents at congested and free flow condition (no shortest route connecting to Palashi Fire Station during free flow). It is clear that due to the location of Siddiq Bazar and Kotowali Fire Station, these two serves 
most of the study area during any roadway conditions. Siddique Bazar fire station is closest to most of the localities in congested roadway conditions (23 localities) than free-flow condition (22 localities).

The shortest path with only one criterion chose the path with the least length when the average travel speed is same in particular roadway section. Besides, the multi-criteria optimum route choses the route with the least friction and with the least travel time for quickest response. Therefore, from a certain locality, the closest fire service station is different in different conditions.

Finding out the service area of each fire station is a much more comprehensive way to determine the most vulnerable localities during any kind of fire incidents. To find the service area of the four fire stations for both roadway conditions (with friction and without friction), Service Area tool of network extension has been used. The Service Area solver is also based on Dijkstra's algorithm to traverse the network. The goal is to return a subset of connected edge features such that they are within the specified network distance or cost cutoff; in addition, it can return the lines categorized by a set of break values that an edge may fall within. From the analysis without network friction, it is found that almost the whole area can be reached from any of the four firefighting stations within 10 minutes (Fig. $\mathbf{5}(\mathbf{c})$ ). To entirely cover the area, 15 minutes response time will be adequate, and the area near Babubazar has the maximum response time of greater than 10 minutes (less than 15 minutes). Considering the scenario during peak hour or congested roadway condition, it is found that most of the study area falls beyond the reach of 15 minutes response zone from any of the four fire stations.

To locate the most vulnerable localities, another service area analysis is done using cut off value up to 45 minutes. The result found should be a major concern for the planners. With the current road network condition, the four fire stations can only reach $14.28 \%$ of the area within 15 minutes of any incident leaving $85.72 \%$ of the area vulnerable to fire hazards. It is seen that more than $10 \%$ area cannot be reached even within 45 minutes from any of the fire stations.

Raster analysis is done to pinpoint the exact localities which are in high-risk zones with the cell size of 150 meters by 150 meters using travel time by car as impedance factor in the friction modeled road network. As Siddiq Bazar fire station is the largest facility in the area and the number of resources and manpower it possesses is greater than the other three fire station combined. The localities those are closer to the Siddique Bazar fire station has a response time from 0.7 minutes to 7 minutes. The farthest area from the station has response time of 14.806 minutes. In an improved network with reduced network friction the average travel times from four fire stations to particular localities have found to reduce significantly. For an improved network, least response time is 0.13 minute compared to 11.7 minutes and the largest response time is 11.6 minutes compared to 20.72 minutes of prior analysis (Fig. 6). Hence merely reducing or controlling the friction points the response time can be decreased by $44 \%$ to $98.9 \%$ in some cases. 


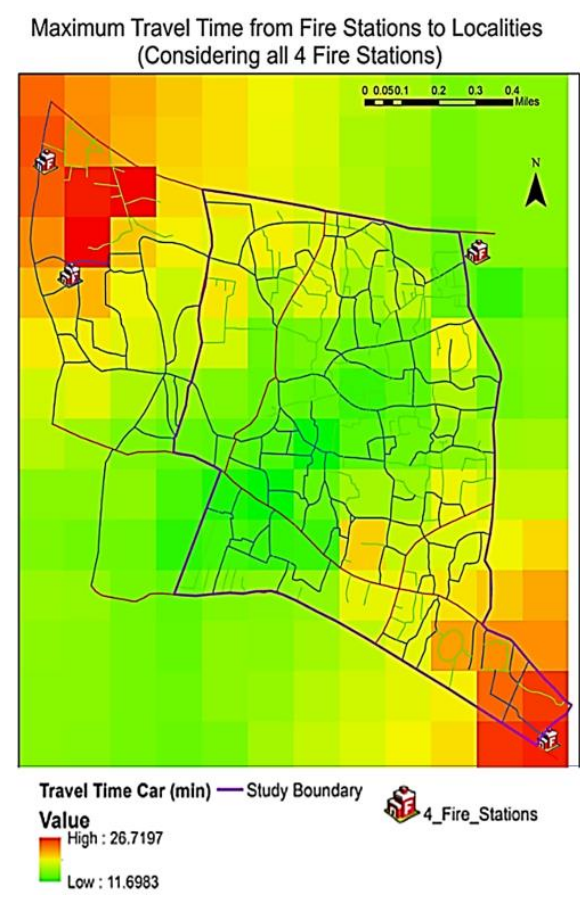

(a)

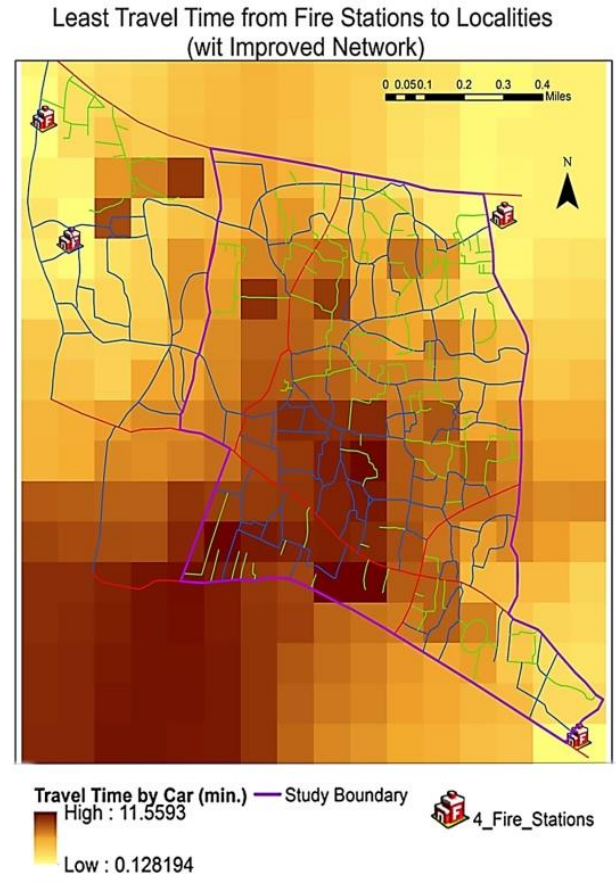

(b)

Fig. 6. Illustration of the degree of dependence between mean of night-time light and GDP at county level.

According to National Fire Protection Agency, a six-minute standard response time for all career fire departments are set (Park et al., 2016), and recommends that the six-minute goal should be achieved 90 percent of the time. Response time standards are not set by Bangladesh Fire Service and Civil Defense Authority and should be developed on an urgent basis. This standard will serve as a base for selecting better potential sites before putting other factors into consideration.

\subsection{Response Time for Closest Health Facilities}

Traditionally, the aim of a facility location problem model is to help reduce costs or increase benefits, however, in respect of emergency service delivery, the objective is often to minimize the barest minimum losses of lives and properties to the community (Aly \& White, 1978). To find out the response time to any nearby medical facilities, the hospitals with emergency units and ambulance services have been identified and located in the map and travel time from the different localities to hospitals was measured and it is found that some of the localities have increased response time up to $950 \%$ (Fig. 7(a)), however, in respect to an increase in travel time value, the highest increase is 39 minutes. Raster analysis has also been done to find the localities with higher average travel times from the four hospitals Fig. 7(b). It has been found that the average travel times of the four hospitals ranges from a minimum of 7.4 minutes to a maximum of 20.7 minutes. 


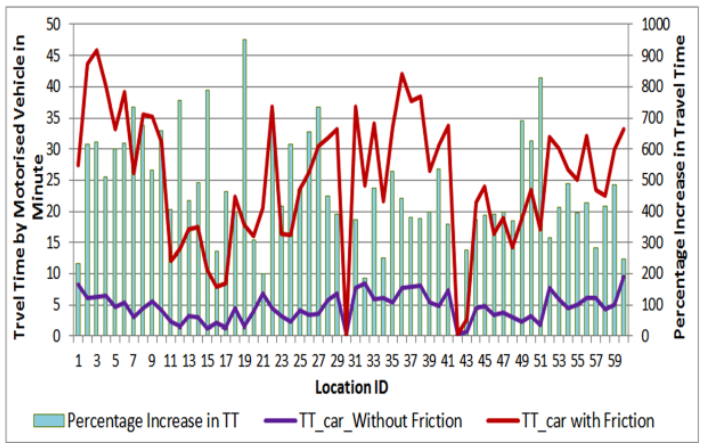

(a)

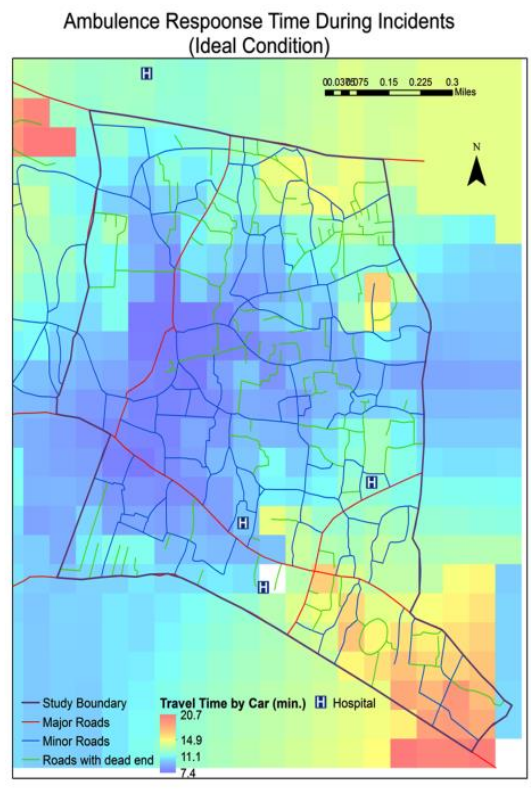

(b)

Fig. 7. Emergency Responses to Medical Facilities: (a) Least Travel Time to Nearest Hospitals from Different Localities of Study Area; and (b) Raster Map Showing Average Travel Time to Four Hospitals from Different Localities of Study Area.

\subsection{Evacuation}

The process of evacuation planning is done in three steps. Firstly, determination of safe areas; secondly, determination of optimum path between building blocks and safe areas, and finally grouping of building blocks relating to each safe area (Naghdi et al., 2008). For reducing the displacement time and distance, the safer area connected by optimum routes must be selected. In this study, based on the accessibility and distance from to the major roads, 27 evacuation points are marked around the study area. These evacuation points are situated at the boundary roads of the study area and at or near to the major roads. Using the developed network and closest facility location of Network Extension, the closest evacuation points are mapped in the Study Area. To select the closest evacuation points, the lengths of the links have been selected as the impedance criteria. The distance of the closest evacuation point from any locality has been found to be as low as 73 meters to as high as 1095 meters. We have marked the location IDs which have an emergency evacuation point at a distance greater than 500 meters.

\subsection{Most Vulnerable Sites during Disaster}

The most vulnerable sites are selected as the sites which have emergency fire service and medical response greater than 30 minutes away and evacuation points greater than 500 meters away. Based on these criteria, the most vulnerable sites are the people living in the following localities highlighted in Fig. 8(a). The localities and landmarks included in the most vulnerable site list are Armanian Church, Armanina School, Tara Mosjid, residential and small commercial areas under Bakshibazar, Armanitola, Bangshal, Nimtoli etc. The 
location of Central Jail has also been marked as one of the vulnerable areas, which is at present open for visitors as the facility has been moved to a different location.

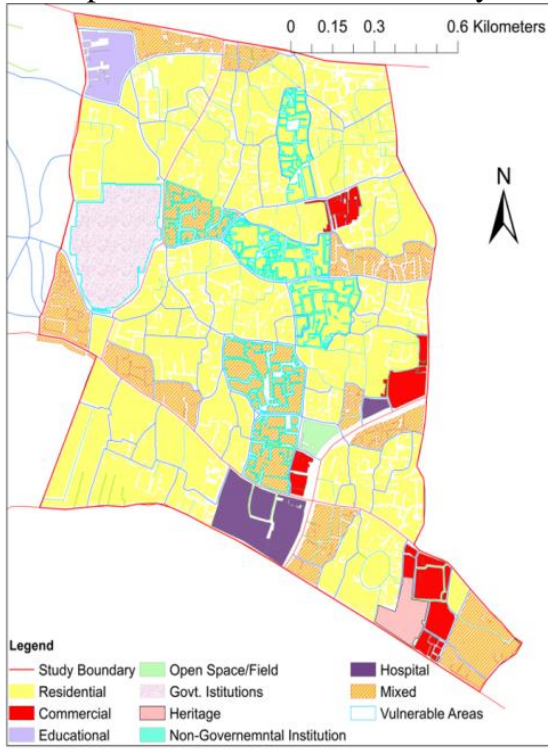

(a)

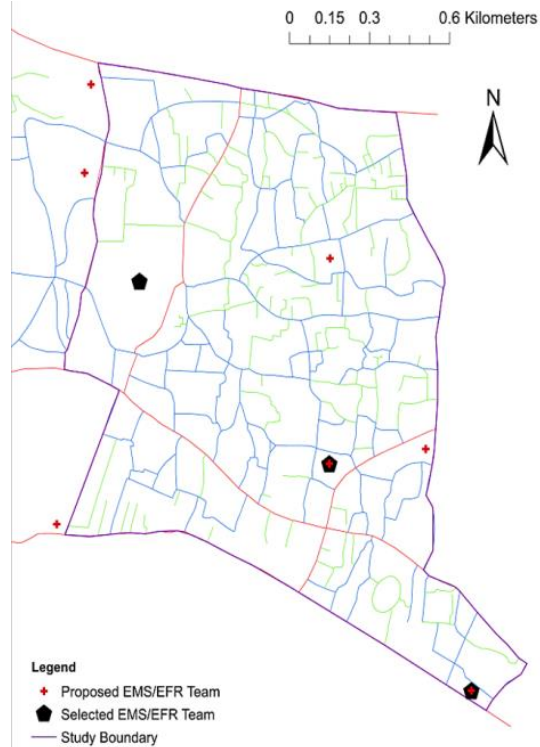

(b)

Fig. 8. Locating EMS/EFR Units: (a) Selected Most Vulnerable Sites (Highlighted); and (b) Proposed Location of EMS/EFR Units using Location-Allocation Tool (to maximize the Coverage Areas).

\subsection{Locating Emergency Response Units}

Some EMS and Emergency Fire Response team are required as a quick response to minimize the damages in the study area. So, with EMS some emergency vehicles to be used for emergency response to fire hazards are also proposed in this study. Eight sites have been proposed to establish temporary emergency units. These sites are located in the available open spaces, and also the central jail site. Among the eight proposed sites, three sites have been located with maximum coverage which is shown in Fig. 8(b). The criteria for selecting the best three locations were set in such a way such that the units can respond within 10 minutes of any incident reported. The unit may consist of a single ambulance and fire vehicle with sufficient manpower to respond to any small to medium accidental incidents before the actual one arrives. These units will help to reduce the damages in the most vulnerable sites located earlier.

\section{CONCLUSIONS AND RECOMMENDATIONS}

In developing countries high population density and unplanned growth increase the damage risks during any disastrous situation. Developing countries also have major drawbacks in using advanced analysis tools as they do not have baseline data frames. This study is an example of how effectively GIS-based analyses can be utilized in disaster management by incorporating baseline data into a spatial format.

This study proposes an optimum route model by considering the actual roadway network frictions of old Dhaka. Current scenarios of disaster response have been assessed using spatial analysis tools of ArcGIS. The major facilities considered in this study are the response time from nearby firefighting stations and medical centers/hospitals. For ground 
evacuation during events like earthquake, we proposed several evacuation points and found the distance from different localities. From the analyses, we pointed out the most vulnerable locations exposed to maximum damages during any disastrous situation. As the land use of the study area is impossible to re-shape to install new roads or to widen the existing roadways, we have to come up with innovative measures. To lessen the expected damages of the most vulnerable areas some EMS and/or EFR unit has been proposed in different locations using location-allocation analysis by maximizing the coverage area. Establishing these mobile facilities will ensure an emergency response within 10 minutes of any incidents. These will provide initial support until the major services reach the affected locations.

This study has several limitations. The transportation network is inherently dynamic because the state and measures of traffic change over time. We neglected the dynamic characteristics of the traffic volume during different times of the day in developed optimum route model. Sufficient historical traffic flow data is required to develop a dynamic optimum route model for the whole city with higher accuracy.

Decision makers rely on information to arrange rescue tasks and allocate relief resources after any an emergency incident. An integrate information value theory coupled with GIS graph theory can be developed to prioritize information items based on their contributions to the successes of potential response and rescue tasks during disaster. There is no database or management information system in DCC. They do not have a GIS for roads, drains and footpaths etc. (CDMP, 2010). The authority must take timely initiatives to prepare, preserve and update this information for a citywide disaster response and management planning.

Despite the limitations, proposed state of practice spatial analyses method is one of the few studies done for disaster management in developing countries. The methodology can be utilized in different spatial scales for different localities. This study demonstrates the disaster preparedness for a built-up urban area, but the methods can be applied at the planning stages of any urban developments. This will ensure the prevention of potential damages during disastrous situations.

\section{ACKNOWLEDGEMENT}

The authors would like to express thanks to the committee for advanced studies and research (CASR) of Bangladesh University of Engineering \& Technology (BUET) for financial support.

\section{R E F E R E N C E S}

Alam, M. J. B. \& Baroi, G. N. (2004) Fire hazard categorization and risk assessment for Dhaka city in GIS framework. Journal of Civil Engineering (IEB), 32(1), 35-45.

Aly, A. A. \& White, J. A. (1978) Probabilistic Formulations of the Emergency Service Location Problems. The Journal of the Operational Research Society, 29 (12),1167-1179.

Amdahl, G. (2001). Disaster Response: GIS for Public Safety. 1st ed. California: Redlands, California, ESRI Press.

Ansary, M. A. \& Choudhury, J. R. (2003) Risk Due to Natural Disasters in Dhaka City and Measures for Mitigation. Proceedings of International Workshop on Disaster Management. EMI. Mumbai, India, 80-100.

Azad, S. Y., Bahauddin, K. \& Salahuddin, T. M. (2013) Disaster Management through Mobile Technology: A Conceptual Model for Bangladesh. Bangladesh Research Publications Journal, $8(1), 34-40$. 
CDMP (2010). Report on Earthquake Risk Assessment of Dhaka, Chittagong and Sylhet City Corporation Area. Dhaka, Bangladesh: Govt. of the People's Republic of Bangladesh.

Chang, N. B., Wei, Y. L., Tseng, C. C. \& Kao, C.Y. (1997) The design of a GIS-based decision support system for chemical emergency preparedness and response in an urban environment. Computers, Environment and Urban Systems, 21(1), 67-94.

Church, R. L. (1997) Geographical information systems and location science. Computers and Operations Research, 29 (6), 541-562.

Church, R. L. \& Cova, T. J. (2000) Mapping evacuation risk on transportation networks using a spatial optimization model. Transportation Research Part C: Emerging Technologies, 8 (1-6), 321-336.

Cova, T. J. \& Church, R. L. (1997) Modeling community evacuation using GIS. International Journal of Geographical Information Science, 11(8), 763-784.

Difani, C. \& Dolton, L. (1992) Battling the Oakland fire with GIS. GIS World, 5(1), 43-45.

Dunn, C. E. \& Newton, D. (1992) Optimal routes in GIS and emergency planning applications. Area, 24(3), 259-267.

Emani, S., Ratick, S. J., Clark, G. E. \& Dow, K. (1993) Assessing vulnerability to extreme storm events and sea-level rise using geographical information systems (GIS). Proceedings of GIS/LIS'93. Bethesda, ACSM/ASPRS, 201-209.

Goodchild, M., Parks, B. \& Steyaert, L. (1994) Environmental modelling with GIS. Oxford: O.U.P.

Gunes, A. E. \& Kovel, J. P. (2000) Using GIS in emergency management operations. Journal of Urban Planning and Development, 126 (3), 136-149.

Haidu, I. \& Nicoara, M. E. (2011) GIS Procedure for the identification of existing infrastructure in the flooding areas. Geographia Technica, 6(2), 30-34.

Hoyos, M. C., Morales, R. S. \& Akhavan-Tabatabaei, R. (2015) OR Models with Stochastic Components in Disaster Operations Management: A Literature Survey. Computers \& Industrial Engineering, 82, 183-197.

Islam, M. M. \& Adri, N. (2008) Fire hazard management of Dhaka City: addressing issues relating to institutional capacity and public perception. Jahangirnagar Planning Review, 6, 57-67.

Islam, M. R. (2018) Performance Evaluation of Flyovers Constructed over Level Crossings in Dhaka City. M.Sc. Thesis, Bangladesh University of Engineering and Technology, Dhaka, Bangladesh.

Ivan, K. \& Haidu, I. (2012) The spatio-temporal distribution of road accidents in Cluj-Napoca. Geographia Technica, 16 (2), 32-38.

Kamal, M. (2008) GIS Based Flood Risk Assessment: A Case Study on Three Wards of Dhaka City. Available from: ttp://www.bip.org.bd/SharingFiles/journal_book/20140427152731.pdf [Accessed 12 Nov. 2017].

Laefer, D. F. \& Pradhan, A. R. (2006) Evacuation route selection based on tree-based hazards using light detection and ranging and GIS. Journal of Transportation Engineering, 132 (4), 312-320.

Mahmud, S. S. \& Hoque, M. S. (2010) Unplanned Development and Transportation Problems in Dhaka City. Published in the two days workshop on Risk Resilient Infrastructures: Role of Education and Training Organized by Buet-Japan Institute of Disaster Prevention and Urban Safety (Buet-Jidpus) Comprehensive Disaster Management Program (CDMP). UNDP Ministry of Food and Disaster Management, Government of Bangladesh as a key note paper, 13-14 November.

Maniruzzaman, K. M., Okabe, A. \& Asami, Y. (2001) GIS for cyclone disaster management in Bangladesh. Geographical and Environmental Modelling, 5 (2), 123-131.

Martin, X. (2011) The Global Competitiveness Report 2011-2012. World Economic Forum Geneva, Switzerland. Available from: http://www3.weforum.org/docs/WEF_GCR_Report_2011-12.pdf [Accessed 12 Nov. 2017]. 
Mitchell, A. (1998) Zeroing in Geographic Information Systems at Work in the Community: Geographic Information Systems at Work in the Community. Redlands, Calif: Environmental Systems Research Institute.

Montoya, L. (2003) Geo-data acquisition through mobile GIS and digital video: an urban disaster management perspective. Environmental Modelling \& Software, 18 (10), 869-876.

Naghdi, K., Mansourian, A., Valadanzoej, M. J. \& Saadatseresht, M. (2008) Evacuation planning in earthquake disasters, using RS \& GIS. International Archives of the Photogrammetry, Remote Sensing and Spatial Information Sciences, 4 (1), 1671-1676.

Nicoară, M. E. \& Haidu, I (2011) Creation of the roads network as a network dataset within a geodatabase. Geographia Technica, 6 (2), 81-86.

Nicoară, P. S. \& Haidu, I. (2014) A GIS based network analysis for the identification of shortest route access to emergency medical facilities. Geographia Technica, 9 (2), 60-67.

Panahi, S. \& Delavar, M. (2008) A GIS-based dynamic shortest path determination in emergency vehicles. World Applied Sciences Journal, 3 (1), 88-94.

Park, P. Y., Jung, W.R., Yeboah, G., Rempel, G., Paulsen, D. \& Rumpel, D. (2016) First responders' response area and response time analysis with/without grade crossing monitoring system. Fire Safety Journal, 79, 100-110.

Rahman, N., Ansary, M. A. \& Islam, I. (2015) GIS based mapping of vulnerability to earthquake and fire hazard in Dhaka city, Bangladesh. International journal of disaster risk reduction, 13, 291300.

Sikder, S. K., Nagarajan, M., Kar, S. \& Koetter, T. (2018) A geospatial approach of downscaling urban energy consumption density in mega-city Dhaka, Bangladesh. Urban Climate, 26, 10-30.

Silva, F. N., de Pidd M., \& Eglese, R. (1993) Spatial decision support systems for emergency planning: an operational research/geographical information systems approach to evacuation planning. International Emergency Management and Engineering Conference. San Diego, Society for Computer Simulation, 130-33.

Tishi, T. R. \& Islam, I. (2018) Urban Fire Occurrences in the Dhaka Metropolitan Area. GeoJournal, 1-11. doi: 10.1007/s10708-018-9923-y. 